\title{
In margine a un'epidemia: risvolti linguistici di un virus - II puntata
}

Claudio Marazzini

PUBBLICATO: 02 APRILE 2020

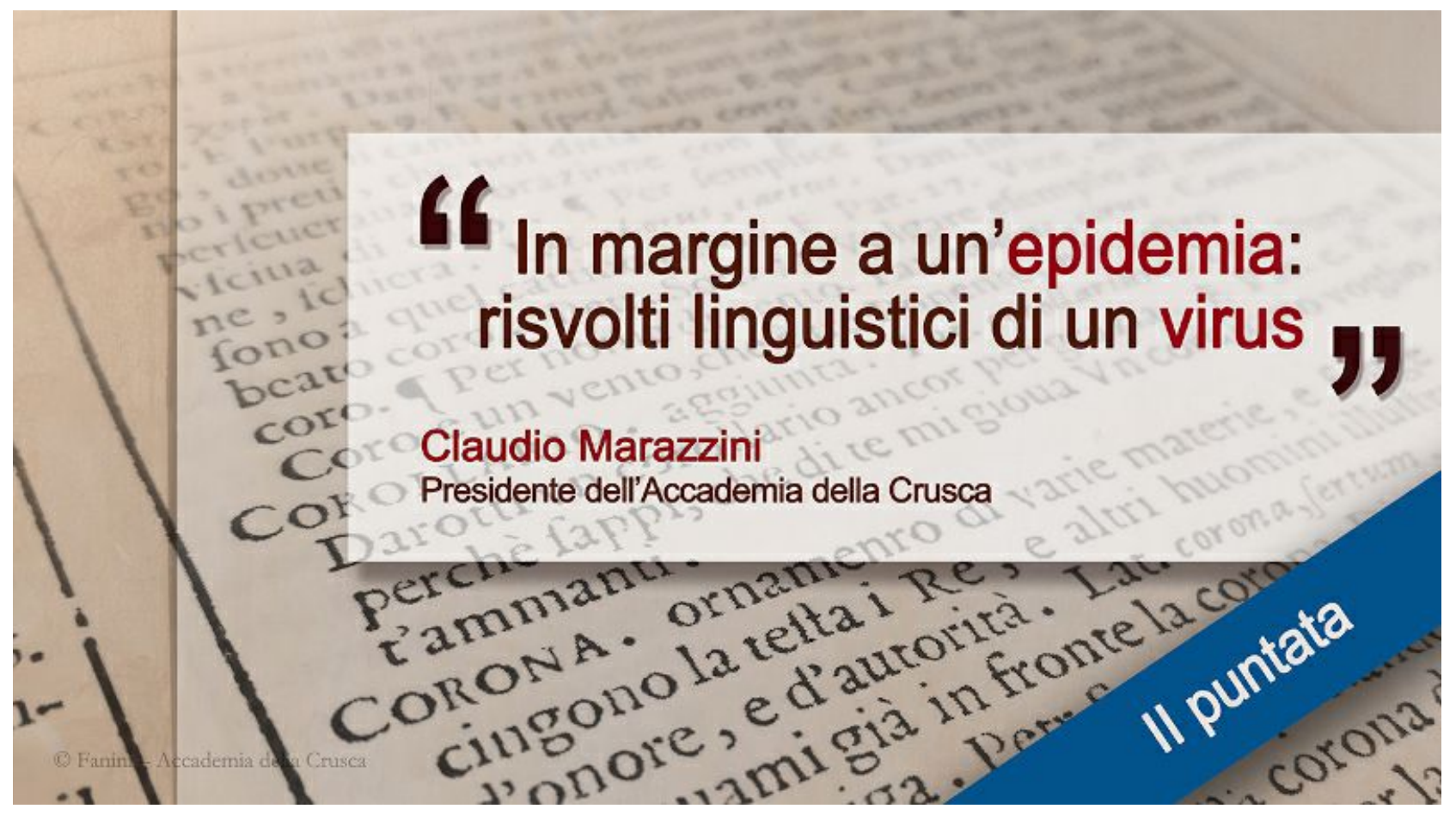

el mese di marzo abbiamo pubblicato un primo intervento dal titolo In margine a
unépidemia: risvolti linguistici di un virus". Successivamente tale intervento ha lasciato il
posto a quello, piu festoso, dedicato al Dantedi.

Ora torniamo al primo argomento, perché ci sono sviluppi interessanti, anche se, ahimè, non ancora legati al "linguaggio della liberazione", di cui speriamo di poter parlare presto, alla fine della pandemia, quando verrà.

Prendiamo lo spunto da alcuni interventi comparsi in questi giorni in Rete.

Il sito Vita.it ha pubblicato un lungo e articolato intervento in cui stigmatizza l'uso di metafore belliche nella comunicazione sociale e giornalistica relativa alla lotta (scusate, ci sono cascato anch'io) al virus. La metafora bellica è sbagliata, secondo Marino Sinibaldi: "E poi una guerra ha un fronte dove stanno alcuni. Qui il fronte non c'è o siamo tutti. La guerra in fondo deresponsabilizza delegando a chi combatte (la prima linea, eccetera eccetera...). Qui siamo tutti responsabili". Altrettanto netto è Massimo Vedovelli: "un'altra comunicazione è possibile? Certo, basata sulla ragione o almeno su un'etica della comunicazione che miri, da un lato a 'lottare contro l'inesprimibile', dall'altro a creare la relazione sociale. Oggi l'uso della metafora bellica sta appiattendo su un'unica modalità la visione dello stare insieme come società complessiva e i fautori dell'odio contro l'altro hanno trovato nel virus e in questa sua narrazione un'ulteriore occasione per alimentare chiusure, barriere, scontri". L'articolo porta anche una mia riflessione, che però è di segno un po' diverso: "La scelta (delle metafore belliche allarmanti) non è questione di lingua, ma di decisione politica. Ovviamente la richiesta di 
mobilitazione rivolta al Paese comporta una tendenza a usare quei termini, anche perché non ci sono precedenti nella collettiva memoria pacifica degli italiani di oggi. E certamente, l'uso delle parole segnala il livello di allerta che il Governo ritiene opportuno in un determinato momento, e la ricezione di quest'uso determina una commisurata reazione della comunità". Avrà ragione Sinibaldi che stigmatizza le metafore belliche come "miseria del nostro immaginario"? Forse sì. Ma come si può pensare alla mobilitazione (di nuovo lessico militare) della gente senza usare un linguaggio allarmante e allarmato? La rinuncia al linguaggio bellico e bellicoso non è forse frutto di unutopia, seppure ispirata a un sentimento lodevole quanto aristocratico, un sentimento che rischia di essere moralmente ineccepibile, quanto poco efficace sul piano pragmatico? Il problema è comunque interessante: una specie di questione del "linguaggio politicamente e moralmente corretto in tempi di pandemia". Una nota: pandemia non spaventa più di epidemia, contrariamente alle mie ipotesi iniziali. Infatti la maggior parte degli italiani non coglie affatto il significato greco di "pan-".

Una speciale attenzione stanno suscitando i nuovi anglismi veicolati con dovizia dalla comunicazione giornalistica legata all'emergenza. Il sito blog.terminologiaetc.it ha definito "anglismo inquietante" il Covid Hospital; ha denunciato l'equivoco del Droplet inteso come "norma e criterio della distanza per evitare il contagio"; ha contestato la legittimità di smart working e di smart schooling: le forme ora in atto non sarebbero smart working ma telelavoro, cosa di per sé discutibile e discussa di fatto, perché il telelavoro è in realtà altra cosa, anche se è vero che quello ora diffuso in gran fretta, più che essere "smart working", assomiglia a una sorta di "lavoro d'emergenza". Con rammarico devo notare che smart working sta soppiantando il nostro "lavoro agile", che pure esiste e anche si difende come può. Per quanto si debba accordare fiducia limitata al motore di ricerca di Google (in questo caso interrogato con stringa virgolettata per avere maggior precisione), "smart working" totalizza "circa" 8.440.000 risultati, "lavoro agile" circa 805.00o. L'anglismo stravince ai punti, com'era prevedibile.

Un lungo articolo pubblicato nel sito della Treccani, a firma di Daniela Pietrini, riesamina la storia della parola coronavirus (già discussa da altri, tra cui il linguista Sgroi, ripreso nel il nostro sito, quando prendemmo lo spunto dal "coronavairus" del ministro Di Maio). Daniela Pietrini ha aggiunto all'elenco del lessico emergenziale alcune neoformazioni (cretinavirus o covidiota: per quelli che non rispettano le norme del governo; pauravirus; coronabond, corona-caos, corona-crisi; Corona-Party: festa organizzata dagli incuranti dei divieti; corona-fake: notizia falsa sul virus) o combinazioni lessicali che hanno trovato modo di circolare, come furbetti della zona rossa, della spesa, della passeggiata, del test del tampone, delle uscite, delle seconde case, del divieto, del decreto, del contagio, del fine settimana, della quarantena, fino ai furbetti del coronavirus. Una bella rassegna, mi pare, di probabili occasionalismi, che mostrano la virtù inventiva degli scriventi italiani, a cui la quarantena non ha tolto il brio della scrittura. A proposito: sulla parola quarantena molti hanno discusso a lungo in questo periodo, chiedendosi se dovesse durare proprio quaranta giorni; la risposta risolutiva sta nel sito della Crusca.

Il direttore del "Resto del Carlino", infine, rispondendo a un lettore, è tornato sul tema degli anglismi. Cosi aveva scritto il sig. Angelo Ravaglia:

Bologna, 29 marzo 2020 - Oltre alla pandemia dilaga l'anglomania: lockdown, smartworking, checkpoint, cluster, triage, drive-thru, runner, test, clinic trial, whatever it works.....il virus mondiale diffonde con sé anche la lingua della globalizzazione. Oggi, senza conoscere questi anglicismi non si può fronteggiare l'emergenza. Oppure occorre chiamare Amazon per farsi recapitare a domicilio un dizionario di inglese. Ah, perfida Albione... niente hanno da dire i Soloni della Crusca di fronte a questa invasione nel nostro lessico, proprio nell'anno di Dante, padre della lingua italiana? Ideona: dobbiamo tradurre tutto in inglese, solo cosi ci salveremo. Come si dirà tampone o mascherina? Oh yeah....alla faccia della Brexit!

Stay home ... anzi stasiv a cà, come si dice in dialetto! 
Il direttore si è complimentato con il lettore, e altrettanto faranno ora i Soloni della Crusca, salvo osservare, puntigliosi come sono, che triage, ormai stabilmente affermato da anni in tutti gli ospedali d'Italia con i simpatici protocolli colorati, non è inglese ma francese.

Aggiungerò una notizia golosa. Il gruppo Incipit, che propone possibili alternative ai termini stranieri, ha avviato una discussione sulockdown, che potrebbe essere detto, a scelta, confinamento o segregazione, anche se l'uso prevalente, nella comunicazione italiana di questi giorni sembra alludere piuttosto alla chiusura forzosa degli esercizi commerciali e delle fabbriche, e finisce quindi per equivalere a serrata o chiusura obbligatoria o obbligata (lo ha osservato, nel corso del dibattito interno a Incipit, il linguista e accademico Michele Cortelazzo).

Incipit non ha ancora emesso il suo verdetto, ma certo la fortuna ormai irresistibile di lockdown fa molto riflettere. Che cosa vuol dire in inglese? Ecco la paginetta dell'Oxford dictionary edizione per telefonino (bellissimo vocabolario, che la Crusca molto invidia agli amici anglosassoni):


Come si vede, il termine non è inglese di Oxford, ma americano. Viene dal linguaggio carcerario. Il paradosso sta nel fatto che gli interventi di limitazione della libertà personale per l'emergenza sanitaria, tra cui l'isolamento sociale (che ai cruscanti piacerebbe di più come isolamento interpersonale), sono stati presi prima da noi, e in seconda battuta dagli altri paesi, spesso costretti a imitarci loro malgrado. I provvedimenti di lockdown sono stati presi molto tardi soprattutto dagli americani e dagli inglesi, che prima ci scherzavano sopra. Eppure, nonostante ciò, abbiamo sentito il bisogno di usare un'espressione non italiana, forse perché suonava meno spaventosa del più crudo segregazione, o forse perché si è messo in atto il solito procedimento: attribuire a una parola straniera assolutamente ignota agli italiani un significato tecnico molto specifico (in questo caso: isolamento e chiusura a causa di restrizioni sanitarie), un significato che magari manco si è stabilizzato nella lingua originaria, e poi far circolare questa parola al posto delle nostre, chiare e trasparenti.

* Jean Claude Egger, Capo sostituto della Sezione "Legislazione e lingua" presso la Cancelleria federale svizzera, segretario della Sottocommissione di lingua italiana della Commissione di redazione 
dell'Assemblea federale elvetica, membro del gruppo Incipit, ci ha segnalato che anche nel mondo germanofono si dibatte sulla legittimità del lockdown: https://www.bluewin.ch/de/leben/lifestyle/lockdown-und-andere-coronische-anglizismen-374716.html.

\section{Cita come:}

Claudio Marazzini, In margine a un'epidemia: risvolti linguistici di un virus - I/ puntata, "Italiano digitale", 2020, XIII, 2020/2 (aprile-giugno)

DOI: $10.35948 / 2532-9006 / 2020.3321$

\section{Copyright 2020 Accademia della Crusca}

Pubblicato con licenza creative commons CC BY-NC-ND 